\title{
BioOne
}

\section{5-HTTLPR Polymorphism: Analysis in South African Autistic Individuals}

Author(s): Zainunisha Arieff, Mandeep Kaur, Hajirah Gameeldien, Lize van der Merwe, and Vladimir B. Bajic

Source: Human Biology, 82(3):291-300.

Published By: Wayne State University Press

DOI: http://dx.doi.org/10.3378/027.082.0303

URL: http://www.bioone.org/doi/full/10.3378/027.082.0303

BioOne (www.bioone.org) is a nonprofit, online aggregation of core research in the biological, ecological, and environmental sciences. BioOne provides a sustainable online platform for over 170 journals and books published by nonprofit societies, associations, museums, institutions, and presses.

Your use of this PDF, the BioOne Web site, and all posted and associated content indicates your acceptance of BioOne's Terms of Use, available at www.bioone.org/ page/terms_of_use.

Usage of BioOne content is strictly limited to personal, educational, and noncommercial use. Commercial inquiries or rights and permissions requests should be directed to the individual publisher as copyright holder. 


\title{
5-HTTLPR Polymorphism: Analysis in South African Autistic Individuals
}

\author{
ZAINUNISHA ARIEFF, ${ }^{1}$ MANDEEP KAUR, ${ }^{2}$ HAJIRAH GAMEELDIEN, ${ }^{1}$ LIZE VAN DER \\ MERWE, ${ }^{3,4}$ AND VLADIMIR B. BAJIC ${ }^{2}$
}

\begin{abstract}
The serotonin transporter promoter length polymorphism (5hydroxytryptamine transporter length polymorphism; 5-HTTLPR) has long been implicated in autism and other psychiatric disorders. The use of selective serotonin reuptake inhibitors (SSRIs) has a positive effect on treating some symptoms of autism. The effects of these drugs vary in individuals because of the presence of the $S$ or $L$ allele of 5-HTTLPR. Studies performed on various autistic populations have found different allele frequencies for the $L$ and $S$ alleles. Allele frequencies and genotypes of the South African autistic populations (African, mixed, and Caucasian) were compared with matching South African ethnic control populations. The $* S / * S$ genotype was found to be highly significantly associated with all the South African autistic ethnic populations. In the South African African population the $* S / * S$ genotype was present in $7(33 \%)$ of the autistic individuals but in none of the control subjects, yielding infinitely large odds of developing autism. The odds of developing autism with the $* S / * S$ genotype compared to the $* L / * L$ genotype increased 10.15-fold in the South African mixed group and 2.74-fold in the South African Caucasian population. The allele frequency of the South African autistic population was also compared with studies of other autistic populations around the world, and highly significant differences were found with the Japanese, Korean, and Indian population groups. The difference was not significant for the French, German, Israeli, Portuguese, and American groups. This is the first South African study of autistic individuals of different ethnic backgrounds that shows significant differences in allele and genotype frequencies of 5-HTTLPR. The results of this study open new avenues for investigating the role of transmission of the $L$ and $S$ alleles in families with autism in South Africa.
\end{abstract}

\footnotetext{
${ }^{1}$ Department of Biotechnology, University of the Western Cape, Private Bag X17, Bellville 7535, Cape Town, South Africa.

${ }^{2}$ Computational Bioscience Research Center, King Abdullah University of Science and Technology, Thuwal 23955-6900, Kingdom of Saudi Arabia.

${ }^{3}$ Biostatistics Unit, Medical Research Council, PO Box 17090, Tygerberg 7505, South Africa.

${ }^{4}$ Department of Statistics, University of the Western Cape, Private Bag X17, Bellville 7535, Cape Town,
} South Africa.

Human Biology, June 2010, v. 82, no. 3, pp. 291-300.

Copyright $\odot 2010$ Wayne State University Press, Detroit, Michigan 48201-1309

KEY WORDS: SEROTONIN TRANSPORTER, 5-HTTLPR POLYMORPHISM, AUTISM, SELECTIVE SEROTONIN REUPTAKE INHIBITORS (SSRIS), SOUTH AFRICAN POPULATIONS. 


\section{2 / ARIEFF ET AL.}

Autism is a severe disorder of communication and behavior that develops before the age of 3 years. This disorder affects some children from birth or infancy and leaves them unable to form normal social relationships or to develop normal communication skills. The incidence is approximately 1 in 150, and autistic males outnumber females by 4 to 1 (Landa 2008). The unofficial estimated number of South African individuals affected with autism was 270,000 in 2007 (http://www.autismsouthafrica.org). Individuals who have a number of neurogenetic disorders, such as fragile X syndrome, Tourette syndrome, and tuberous sclerosis complex, exhibit some autistic behavior (Choi et al. 2008; Muhle et al. 2004).

Studies thus far have not conclusively shown the cause of autism; however, it does seem that a combination of several factors can cause autism. Twin studies have indicated that a strong genetic etiology exists for autism (Muhle et al. 2004). Identical, or monozygotic (MZ), twins share $100 \%$ of their genetic material, and nonidentical, or dizygotic (DZ), twins share only $50 \%$ of their genetic material. If one $\mathrm{MZ}$ twin has autism, then there is a $60 \%$ chance that the other will also be affected, compared to $0 \%$ in the case of DZ twins (Muhle et al. 2004). However, for broader autism phenotypes that include communication skills and social disorders, an increase in concordance of $60-92 \%$ in MZ twins and up to $10 \%$ in DZ twins has been observed (Muhle et al. 2004).

Neurochemical and neuroendocrine studies suggest that the serotonin transporter gene (SERT) (SLC6A4, MIM 182138) likely plays a role in autism and thus is a potential candidate gene in autistic disorder. Hyperserotonemia has been consistently found in a proportion of autistic patients, and the use of selective serotonin reuptake inhibitors (SSRIs) has been effective in treating some symptoms of autism, such as reducing ritualistic behaviors and related aggression (Kim et al. 2002; Ramoz et al. 2006). This gene is on chromosome $17 \mathrm{q} 11$ and encodes the SERT protein. It is $31 \mathrm{~kb}$ long, consists of 14 exons, and codes for 630 amino acid proteins (Bartlett et al. 2005). Four different polymorphisms of this gene have been reported: (1) a 44-bp insertion/deletion polymorphism in the promoter region, also referred to as 5-HTTLPR; (2) a 380-bp deletion just before the start codon; (3) a 17-bp variable number of tandem repeats in intron 2; and (4) a single nucleotide polymorphism in the $5^{\prime}$ untranslated region (Bartlett et al. 2005; Guhathakurta et al. 2006; Murphy et al. 2004). The promoter polymorphisms - the long $(L)$, short $(S)$, and small number of rare alleles - of the SERT gene have been extensively studied and are known to modulate its expression.

High levels of platelet serotonin have been consistently found in a proportion of autistic patients and their first-degree relatives (Anderson et al. 2004). Furthermore, studies have shown that individuals who are homozygous for the $L$ allele and have such psychiatric disorders as depression or autism show an improvement when treated with SSRI drugs (Pollock et al. 2000; White et al. 2005). Another study showed an association of the $L$ allele of the 5-HTTLPR gene with shyness (Arbelle et al. 2003). The $S$ allele on the other hand has been shown to 
be associated with neuroticism-related traits in a psychiatrically healthy population (Gonda et al. 2008). The $S$ allele is also associated with increased response to emotional stimuli and behaviors such as aggression, anxiety, depression, and suicide. Individuals who had depression and who were homozygous for the $L$ allele had a better response when treated with SSRIs. Individuals with the $S$ allele showed no improvement or their condition worsened when treated with the drugs (White et al. 2005). It is therefore vital to determine an individual's genotype before SSRIs are prescribed to patients.

Studies performed on various autistic populations, such as French, Israeli, Japanese, Koreans, and Indians, found different $L$ and $S$ allele frequencies in these groups (Guhathakurta et al. 2006; Koishi et al. 2006; Tordjman et al. 2001; Yirmiya et al. 2001). A French study of autistic individuals found a high $L$ allele frequency (61\%), the Israeli individuals had equal $S$ and $L$ allele frequencies, and the autistic Japanese, Korean, and Indian individuals had a much higher $S$ allele frequency $(74 \%, 71 \%$, and $63 \%$, respectively).

The allele frequency in the South African autistic population for 5-HTTLPR polymorphism has never been estimated. In addition, the South African autistic population includes a number of different ethnic groups. In an earlier investigation we identified the allele and genotype frequencies of 5-HTTLPR promoter polymorphism in healthy individuals of various ethnic population groups residing in South Africa. A comparison of the genotype distribution of 5-HTTLPR among South African population groups showed no significant differences between the African and mixed population, possibly because both are of African descent or origin. However, the $L$ allele frequencies for the mixed and African groups were higher compared to the frequency for Caucasians (Esau et al. 2008). In the present study, we estimated the genotype and allele frequency distributions of the promoter region of the 5-HTTLPR gene in different ethnic populations in the South African autistic population and compared them to the healthy South African population from our previous paper. In addition, we compared the allele frequencies of the South African autistic population to other autistic population groups from other parts of the world.

\section{Materials and Methods}

Ethical Clearance. Before undertaking the study, we obtained ethical clearance from the University of the Western Cape Ethics Committee and the Western Cape Education Department. We also obtained consent from principals of schools and parents to allow the collection and genetic analysis of DNA samples, in accordance with the Declaration of Helsinki.

Study Group. The present study group is composed of 40 (93\% male, 7\% female) South African autistic Caucasians, 21 (71\% male, 29\% female) South African autistic Africans, and 48 (92\% male, 8\% female) South African autistic "Colored"/mixed individuals. The aim of this study was to estimate and compare 


\section{4 / ARIEFF ET AL.}

the allele distribution of 5-HTTLPR in the present study group to that of healthy South African children studied earlier by Esau et al. (2008). The earlier study group consisted of 342 healthy South African individuals (96 Caucasians, 68 Africans, and 178 “Colored”/mixed).

Sample Collection. Samples were collected from autistic individuals from Cape Town and Gauteng Province (South Africa), and control samples were collected from healthy schoolchildren from primary and high schools in Cape Town. The autistic individuals were selected on the basis of the Junior South African Intelligence Scale (JSAIS) and Senior South African Intelligence Scale (SSAIS) tests, the Griffith Mental Development Scale, and the Bender Visual Test performed by psychiatrists in the respective schools. The clinical data were obtained from school records. Individuals participating in the study were swabbed by taking a sterile swab (Puritan Sterile Polyester Tip Applicators, Manta Forensics, Gauteng, South Africa) and rubbing it against the inside of the subject's cheek for $1 \mathrm{~min}$ and placing it into a labeled sterile 15-ml Falcon tube (Boeco, Hamburg, Germany). This was done for both cheeks.

DNA Extraction. DNA was extracted from the swabs using the BuccalAmp DNA Extraction Kit (Epicentre, Madison, Wisconsin) according to the manufacturer's suggestion. This solution was then stored at $4^{\circ} \mathrm{C}$, and the stock was stored at $-20^{\circ} \mathrm{C}$.

Genotyping. The genotype of the individuals participating in the study was obtained by using the primers designed by Klauck et al. (1997). The sequences of the forward and reverse primers were 5'-GGCGTTGCCGCTCTGAATGC-3' and 5'-GAGGGACTGAGCTGGACAACCAC-3', respectively; the primers were purchased from Inqaba Biotech (Pretoria, South Africa). The PCR reaction contained the following reagents: $3 \mathrm{pM}$ forward primer, $3 \mathrm{pM}$ reverse primer, $1 \times \mathrm{PCR}$ buffer, $100 \mu \mathrm{M}$ dNTPs, $1.5 \mathrm{mM} \mathrm{MgCl} 2,1 \mathrm{U}$ BioTaq, $100 \mathrm{ng}$ DNA, and deionized autoclaved water in a final volume of $25 \mu \mathrm{l}$. The PCR conditions were as follows: an initial denaturation for $5 \mathrm{~min}$ at $95^{\circ} \mathrm{C} ; 35$ cycles at $95^{\circ} \mathrm{C}$ for $30 \mathrm{~s}, 63^{\circ} \mathrm{C}$ for $30 \mathrm{~s}$, and $72^{\circ} \mathrm{C}$ for $1 \mathrm{~min}$; and a final extension at $72^{\circ} \mathrm{C}$ for $10 \mathrm{~min}$. These were the same conditions used in our previous study (Esau et al. 2008).

Gel Electrophoresis. Ten milliliters of PCR product was mixed with $2 \mu 1$ loading dye (Fermentas O'GeneRuler 6× Orange Loading Dye) and loaded alongside a 100-bp DNA ladder (Fermentas O'GeneRuler DNA Ladder Mix) on the gel. The PCR products of the samples were electrophoresed on a $1.2 \%$ agarose gel at a voltage of $70 \mathrm{~V}$ for $1.5 \mathrm{hr}$.

Statistical Analysis. Hardy-Weinberg equilibrium was tested separately in the different groups (healthy control and autistic individuals, stratified by ethnicity) 
using an exact test (Wigginton et al. 2005). Logistic regression models were used to compare subjects with autism to healthy control subjects, with respect to both genotype and allele frequency distributions, known as tests of association, stratified by ethnicity. We also assessed the genotype-autism association in the combined group, adjusted for ethnicity. $P$ values and odds ratios with $95 \%$ confidence intervals are reported from these models. Fisher's exact test was used to compare allelic distributions from published studies of variants of 5-HTTLPR in different autistic populations with the combined South African autistic group.

\section{Results}

The genotype frequencies of the healthy control groups were in HardyWeinberg equilibrium for all three ethnic groups, but the genotype distributions of the autistic patients deviated significantly from Hardy-Weinberg equilibrium in all three ethnic groups (results not shown). We observed four different genotypes in the South African autistic samples: $* L / * L, * L / * S, * S / * S$, and $* L / * X L$. The extra-long $(X L)$ allele has an additional 44-bp insertion. Only two individuals with the $* L / * X L$ genotype were observed, and they were in the autistic Caucasian population. The $* L / * X L$ genotype was not included in the analyses because of its low observed frequencies and its absence in other populations. The $* L / * L, * L / * S$, and $* S / * S$ genotypes are the most commonly occurring genotypes in any given population.

The genotype frequency distributions differed highly significantly between the autistic and control subjects in all three ethnic groups as well as in the combined South African group after adjusting for ethnicity ( $p<0.0001$ for all comparisons). The pattern of genotype associations was that the estimated odds of autism was not significant at all for $* L / * S$ heterozygotes, but for $* S / * S$ homozygotes the odds of autism was highly significant compared to the $* L / * L$ homozygotes (Table 1). This indicates that the effect of the $S$ allele could be dominant and not additive. The allele distributions were significantly different in the African and mixed groups but not in the Caucasian group (Table 1). This is further evidence that the effect is dominant, not additive allelic.

The South African autistic population showed highly significant differences in allele frequency distributions to some of the published populations, namely, Japanese, Korean, and Indian groups $(p<0.0001)$ (Table 2). All three Asian populations had more $S$ alleles than $L$ alleles. The difference in allele frequency distribution was not significant for any of the French, German, Israeli, Portuguese, and American groups, all having more $L$ than $S$ alleles, similar to our findings.

\section{Discussion}

In the present investigation we aimed to identify and compare the allele and genotype frequencies of the 5-HTTLPR promoter polymorphism. We detected a 


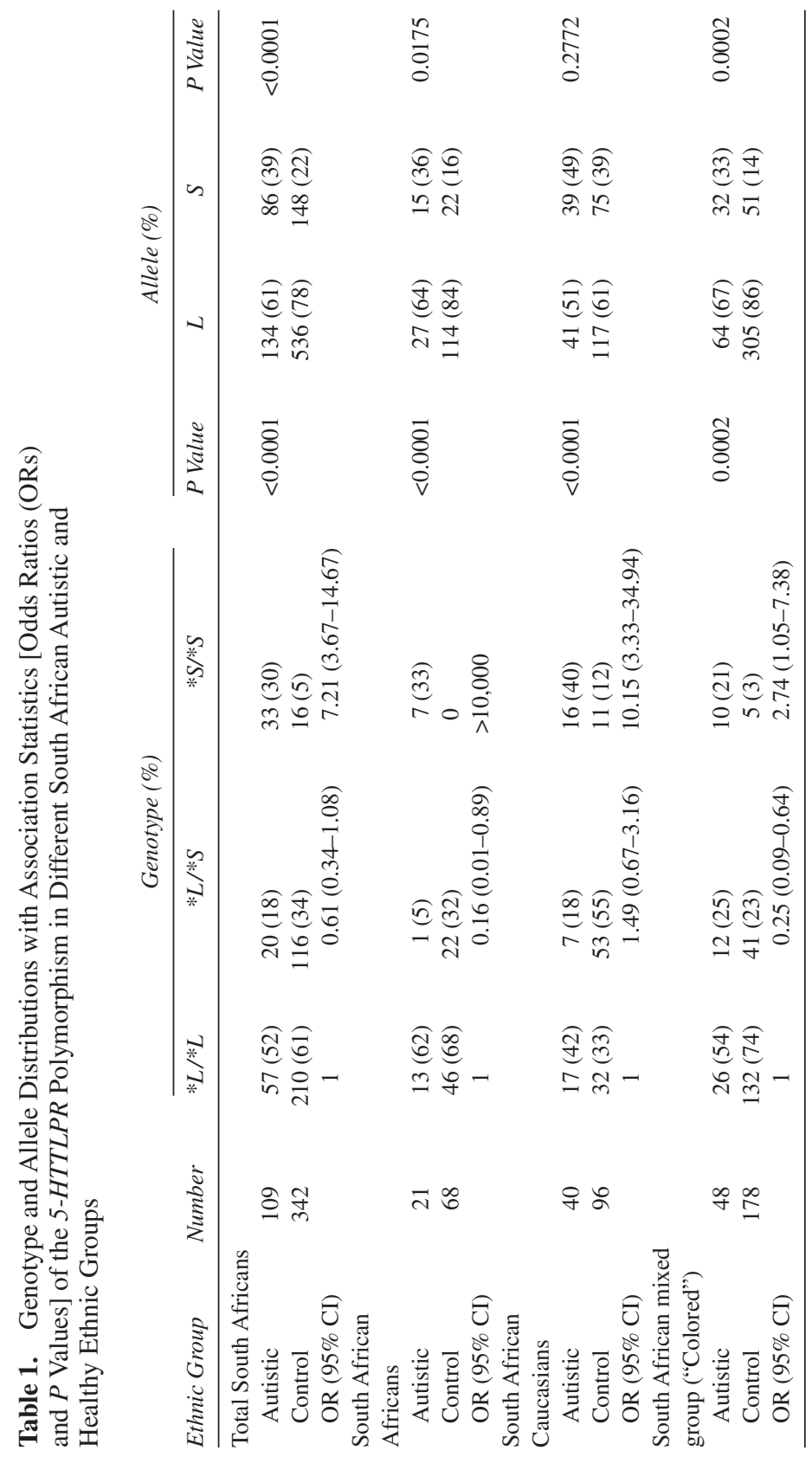


Table 2. Published Studies of Variants of 5-HTTLPR in Different Autistic Populations and Comparison with the South African Autistic Population

\begin{tabular}{|c|c|c|c|c|c|}
\hline \multirow[b]{2}{*}{ Population } & \multirow{2}{*}{$\begin{array}{l}\text { Number of } \\
\text { Individuals }\end{array}$} & \multicolumn{2}{|c|}{ Allele Frequency (\%) } & \multirow[b]{2}{*}{$P$ Value } & \multirow[b]{2}{*}{ Reference } \\
\hline & & $S$ & $L$ & & \\
\hline French & 71 & $55(39)$ & $87(61)$ & 0.9664 & Tordjman et al. (2001) \\
\hline Germans & 65 & $40(36)$ & $70(64)$ & 0.7184 & Klauck et al. (1997) \\
\hline Israelis & 33 & $25(38)$ & $41(62)$ & 0.9735 & Yirmiya et al. (2001) \\
\hline Portuguese & 104 & $97(41)$ & $111(59)$ & 0.1392 & Coutinho et al. (2004) \\
\hline French & 45 & $43(48)$ & $47(52)$ & 0.1651 & Betancur et al. (2002) \\
\hline Japanese & 104 & $154(74)$ & $54(26)$ & $<0.0001$ & Koishi et al. (2006) \\
\hline Americans & 72 & $59(41)$ & $85(59)$ & 0.7433 & Zhong et al. (1999) \\
\hline Koreans & 126 & $179(71)$ & $73(29)$ & $<0.0001$ & Cho et al. (2007) \\
\hline Indians & 78 & $98(63)$ & $58(37)$ & $<0.0001$ & Guhathakurta et al. (2006) \\
\hline South Africans & $109^{\mathrm{a}}$ & $86(39)$ & $132(61)$ & & Present study \\
\hline
\end{tabular}

a. Excluding individuals with the $X L$ allele.

highly significant association of the $* S / * S$ genotype, versus the $* L / * L$ genotype, in all the South African autistic ethnic populations compared with the healthy South African control group (Table 1). In the South African African population the $* S / * S$ genotype increased the odds of developing autism more than 10,000 fold; in the South African mixed group, the odds increased 10.15-fold, and in the South African Caucasian group, 2.74-fold (see Table 1).

A number of other studies have shown conflicting evidence regarding the preferential inheritance of the $S$ and $L$ variants of 5-HTTLPR in individuals affected with autism. In general, the $L$ allele is predominant in all the South African autistic and healthy populations (see Table 2) (Esau et al. 2008). Our investigation is limited to individuals affected with autism, and their parents were not included in the study. Therefore we cannot comment on the preferential transmission of alleles in the South African group. But there are studies in the literature that address this issue. A preferential inheritance of the $L$ variant of 5-HTTLPR in affected individuals was observed in French, German, Israeli, Portuguese, and American autistic populations (Table 2) (Coutinho et al. 2004; Klauck et al. 1997; Tordjman et al. 2001; Yirmiya et al. 2001; Zhong et al. 1999). However, Cook et al. (1997), using a transmission disequilibrium test (TDT), reported that the $S$ variant of 5-HTTLPR was preferentially transmitted from parents to autistic children. A similar finding was observed in a Japanese, Korean, and Indian autistic study (Table 2). Another study on an Irish autistic population showed that there is preferential transmission of the $S$ allele in all 84 families that were genotyped (Conroy et al. 2004). Another research group found that neither the $L$ nor the $S$ variant of 5-HTTLPR was preferentially inherited by individuals affected with autism (Table 2) (Betancur et al. 2002).

Studies show that the SERT variants play a role in the behavioral expression of autism. Tordjman et al. (2001) observed greater $S$ allele transmissions in 
severely impaired individuals and greater $L$ allele transmission in moderately impaired individuals. The data obtained by Tordjman's et al. (2001) suggest that the $L$ and $S$ alleles of the 5-HTTLPR gene by themselves do not convey risk for autism but rather modify the severity of autistic behaviors. In another study, Arbelle et al. (2003) observed a significant association between the $L$ allele of the 5-HTTLPR polymorphism and shyness in schoolchildren. A more recent study has shown an association of the $S$ allele of the 5-HTTLPR gene with neuroticism-related traits and temperaments in a psychiatrically healthy population (Gonda et al. 2008). 5-HTTLPR polymorphism has been shown to influence the cerebral cortical gray matter volumes in 44 male children (2-4 years old) with autism. The $S$ allele was linked with increasing gray matter volume (Wassink et al. 2007). The genotypespecific phenotypes for 5-HTTLPR have also been linked to the variation in specific symptoms in individuals with autism (Brune et al. 2006). In one report based on Sardinian children, 5-HTTLPR polymorphism was not linked with autistic spectrum disorders (Guerini et al. 2006). Similar results were observed in Indian autistic individuals, where no association with 5-HTTLPR was found based on case-control studies and family-based approaches (Guhathakurta et al. 2006). The selective transmission of both $L$ and $S$ alleles has been observed in family studies related to autism (Devlin et al. 2005) and certainly warrants further investigation in different ethnic groups and populations. From these findings, it does appear that $S E R T$ variants play a role in the modification of behavioral expression of individuals affected with autism. Therefore, in future assessments of individuals affected with autism, it seems reasonable to determine the 5-HTTLPR genotype of an affected individual in conjunction with his or her behavior patterns.

In conclusion, this is the first South African study that focused on identifying the frequency of alleles of the 5-HTTLPR polymorphism in an autistic population. The $* S / * S$ genotype was found to be highly significantly associated with all the South African autistic ethnic populations. The association of the $S$ allele was significantly associated in the South African autistic mixed group and the total South African autistic group, and therefore SSRI drugs should be prescribed only to South African autistic individuals if they are homozygous for the $L$ variant because individuals with the $S$ allele showed no improvement or their condition worsened when treated with these drugs (White et al. 2005). A future study would be to perform family studies of the South African autistic families to investigate the transmission of the $L$ or $S$ allele in the family situation.

Acknowledgments We would like to thank the National Research Foundation, South Africa (Thuthuka grant TTK2008050600011), Autism South Africa, and the University of the Western Cape for funds provided for this study. We also want to thank the children, their parents, the school staff, and volunteers of the Western Cape Education Department for their support and involvement during the sample collection. We thank Luke Esau, Lucinda Adonis, Muneera Davids, Zaida Dalvie, Cleo Williams, and all the final-year biotechnology student volunteers who so willingly helped us with the sample collection from the different schools. 
Received 15 June 2009; revision accepted for publication 8 February 2010.

\section{Literature Cited}

Anderson, G. M., K. Czarkowski, N. Ravski et al. 2004. Platelet serotonin in newborns and infants: Ontogeny, heritability, and effect of in utero exposure to selective serotonin reuptake inhibitors. Pediatr. Res. 56:418-422.

Arbelle, S., M. Benjamin, H. Golin et al. 2003. Relation of shyness in grade school children to the genotype for the long form of the serotonin transporter promoter region polymorphism. Am. J. Psychiatr. 160:671-676.

Bartlett, C., N. Gharan, J. Millonig et al. 2005. Three autism candidate genes: A synthesis of human genetic analysis with other disciplines. Int. Dev. Neurosci. 23:221-234.

Betancur, C., M. Corbex, C. Spielewoy et al. 2002. Serotonin transporter gene polymorphisms and hyperserotonemia in autistic disorder. Mol. Psychiatr. 7:67-71.

Brune, C. W., S. J. Kim, J. Salt et al. 2006. 5-HTTLPR genotype-specific phenotype in children and adolescents with autism. Am. J. Psychiatr. 163(12):2148-2156.

Cho, I. H., H. J. Yoo, M. Park et al. 2007. Family-based association study of 5-HTTLPR and the 5-HT2A receptor gene polymorphisms with autism spectrum disorders in Korean trios. Brain Res. 1139:34-41.

Choi, Y. J., A. D. Nardo, I. Kramvis et al. 2008. Tuberous sclerosis complex protein control axon formation. Genes Devel. 22:2485-2495.

Conroy, J., E. Meally, G. Kearney et al. 2004. Serotonin transporter gene and autism: A haplotype analysis in an Irish autistic population. Mol. Psychiatr. 9(6):587-593.

Cook, E. H., Jr., R. Courchesne, C. Lord et al. 1997. Evidence of linkage between the serotonin transporter and autistic disorder. Mol. Psychiatr. 2:247-250.

Coutinho, A. M., G. Oliveira, T. Morgadinho et al. 2004. Variants of the serotonin transporter gene (SLC6A4) significantly contribute to hyperserotonemia in autism. Mol. Psychiatr. 9:264-271.

Devlin, B., E. H. Cook, H. Coon et al. 2005. Autism and the serotonin transporter: The long and short of it. Mol. Psychiatr. 10:1110-1116.

Esau, L., M. Kaur, L. Adonis et al. 2008. The 5-HTTLPR polymorphism in South African healthy populations: A global comparison. J. Neural Transm. 115:755-760.

Gonda, X., K. N. Fountoulakis, G. Juhasz et al. 2008. Association of the $S$ allele of the 5-HTTLPR with neuroticism-related traits and temperaments in a psychiatrically healthy population. Eur. Arch. Psychiatr. Clin. Neurosci. 259:106-113.

Guerini, F. R., S. R. Manca, S. Sotgui et al. 2006. A family based linkage analysis of the $H L A$ and 5-HTTLPR gene polymorphisms in Sardinian children with autism spectrum disorder. Hum. Immunol. 67:108-117.

Guhathakurta, S., S. Ghosh, S. Sinha et al. 2006. Serotonin transporter promoter variants: Analysis in Indian autistic and control population. Brain Res. 1092:28-35.

Kim, S. J., N. Cox, R. Courchesne et al. 2002. Transmission disequilibrium mapping at the serotonin transporter gene (SLC6A4) region in autistic disorder. Mol. Psychiatr. 7:278-288.

Klauck, S., I. Poustka, F. Benner et al. 1997. Serotonin transporter (5-HTT) gene variants associated with autism. Hum. Mol. Genet. 6:2233-2238.

Koishi, S., K. Yamamoto, H. Matsumoto et al. 2006. Serotonin transporter promoter polymorphism and autism: A family-based genetic association study in Japanese population. Brain Devel. $2: 257-260$.

Landa, R. J. 2008. Diagnosis of autism spectrum disorders in the first 3 years of life. Natl. Clin. Pract. Neurol. 4:138-147.

Muhle, R., S. Trentacoste, and I. Rapin. 2004. The genetics of autism. Pediatrics 113:472-486.

Murphy, D., A. Lerner, G. Rudnick et al. 2004. Serotonin transporter: Gene, genetic disorders, and pharmacogenetics. Mol. Int. 4:109-123. 


\section{0 / ARIEFF ET AL.}

Pollock, B., R. Ferrel, B. H. Mulsant et al. 2000. Allelic variation in the serotonin transporter promoter affects onset of paroxetine treatment response in late-life depression. Neuropsychopharmacology 23:587-590.

Ramoz, N., J. Reichert, T. Corwin et al. 2006. Lack of evidence for association of the serotonin transporter gene SLC6A4 with autism. Biol. Psychiatr. 60:186-191.

Tordjman, S., L. Gutknecht, M. Carlier et al. 2001. Role of the serotonin transporter gene in the behavioral expression of autism. Mol. Psychiatr. 6:434-439.

Wassink, T. H., H. C. Hazlett, E. A Epping et al. 2007. Cerebral cortical gray matter overgrowth and functional variation of the serotonin transporter gene in autism. Arch. Gen. Psychiatr. 64(6):709-717.

White, K., C. Walline, and E. Barker. 2005. Serotonin transporter: Implications for antidepressant drug development. Am. Assoc. Pharm. Sci. J. 7:421-433.

Wigginton, J. E., D. J. Cutler, and G. R. Abecasis. 2005. A note on exact tests of Hardy-Weinberg equilibrium. Am. J. Hum. Genet. 76:887-893.

Yirmiya, N., T. Pilowsky, L. Nemonov et al. 2001. Evidence for an association with the serotonin transporter promoter region polymorphism and autism. Am. J. Med. Genet. 105:381-386.

Zhong, N., W. Ye, L. Ju et al. 1999. 5-HTTLPR variants not associated with autistic spectrum disorders. Neurogenetics 2:129-131. 